\title{
Enhanced intestinal glucose and alanine transport in cystic fibrosis
}

\author{
P Baxter, J Goldhill, J Hardcastle, P T Hardcastle, C J Taylor
}

\begin{abstract}
The rise in short-circuit current associated with the active transport of glucose and alanine was measured in intestinal biopsy samples from children with cystic fibrosis. The glucose-induced increase in the short-circuit current was greater in the cystic fibrosis tissues than in control samples over the whole range of concentrations tested $(2 \cdot 5-35 \mathrm{mM})$, a reflection of an increased maximum rate of transport. Similar results were obtained with alanine. These findings suggest that active $\mathrm{Na}^{+}$-linked nutrient transport is enhanced in cystic fibrosis.
\end{abstract}

In cystic fibrosis the intestine is characterised by a defect in the apical membrane $\mathrm{Cl}^{-}$channels of the enterocyte, which leads to a failure in $\mathrm{Cl}^{-}$ secretion. ${ }^{1-3}$ This abnormality has also been observed in other $\mathrm{Cl}^{-}$transporting epithelia. ${ }^{4}$ In the normal intestine $\mathrm{Cl}^{-}$channels are activated during active nutrient absorption ${ }^{5}$ and it has therefore been suggested that the absence of functioning $\mathrm{Cl}^{-}$channels in cystic fibrosis could exacerbate the malabsorption that is a feature of this disease. ${ }^{6}$

Since both $\mathrm{Cl}^{-}$secretion and $\mathrm{Na}^{+}$-linked nutrient absorption are active electrogenic processes, they increase transintestinal electrical activity. The rise in short-circuit current induced by activation of these mechanisms can be measured in intestinal biopsy samples using a modified Ussing chamber ${ }^{3}$ and this technique was used to investigate the active transport of glucose and alanine in cystic fibrosis.

\section{Methods}

Departments of Biomedical Science and Paediatrics, The University, Sheffield P Baxter

J Goldhill

J Hardcastle

P T Hardcastle

C J Taylor

Correspondence to:

Dr J Hardcastle, Department

of Biomedical Science, The

University, Western Bank, University, Western

Sheffield S10 2TN.

25 September 1989 unresponsive to changes in pancreatic enzyme supplements. A further two biopsy specimens were taken from operative bowel resections. In each patient the diagnosis of cystic fibrosis was confirmed by at least two consecutive abnormal sweat tests. The mean age of the cystic fibrosis group was 7.6 years (range $0.3-18.6$ years). Twenty seven children with normal sweat tests (mean age 4.8 years, range $0 \cdot 1-14.0$ years) under investigation for chronic diarrhoea or short stature acted as control subjects. In addition, an operative sample was obtained from an infant who presented with ileal atresia and meconium peritonitis but who subsequently had two normal sweat tests. Intestinal morphology was normal in both groups of children.

\section{EXPERIMENTAL PROCEDURE}

The electrical activity of the biopsy specimens was measured as described previously. ${ }^{3}$ Each tissue was mounted as a sheet (exposed area= $0.03 \mathrm{~cm}^{2}$ ) in a modified Ussing chamber and incubated at $37^{\circ} \mathrm{C}$ with $\mathrm{Krebs}$ bicarbonate saline gassed with $95 \% \quad \mathrm{O}_{2} / 5 \% \quad \mathrm{CO}_{2}$. The serosal solution contained $10 \mathrm{mM}$ glucose and the mucosal solution $10 \mathrm{mM}$ mannitol. The potential difference was measured using salt bridge electrodes connected via calomel half cells to a differential input electrometer whose output was displayed on a Vitatron chart recorder (MSE Scientific Instruments, 2001 series). Current was applied across the tissue by $\mathrm{Ag} / \mathrm{AgCl}$ electrodes via wide bore salt bridges. Tissue resistance was determined from the potential difference change induced by a $10 \mu \mathrm{A}$ current pulse, taking into account the resistance of the fluid, which was determined in a similar manner before mounting the tissue. The short-circuit current was then calculated from the potential difference and resistance using Ohm's law. After a 10 minute stabilisation period, potential difference and resistance were measured at one minute intervals. Glucose or alanine was added sequentially to the mucosal compartment to give concentrations of $2.5-35 \mathrm{mM}$, and the rise in the short-circuit current was taken as the difference between the maximum value achieved at each concentration and that immediately before the start of nutrient addition. The effects of the increased osmolarity resulting from the addition of glucose or alanine to the mucosal solution were controlled by measuring the changes in the short-circuit current induced by equivalent concentrations of mannitol.

\section{CHEMICALS}

Mannitol was obtained from May \& Baker Ltd, Dagenham, England; D-glucose and L-alanine from BDH Chemicals Ltd, Poole, England; and acetylcholine chloride from Sigma Chemical Co, St Louis, MO 63178, USA. 


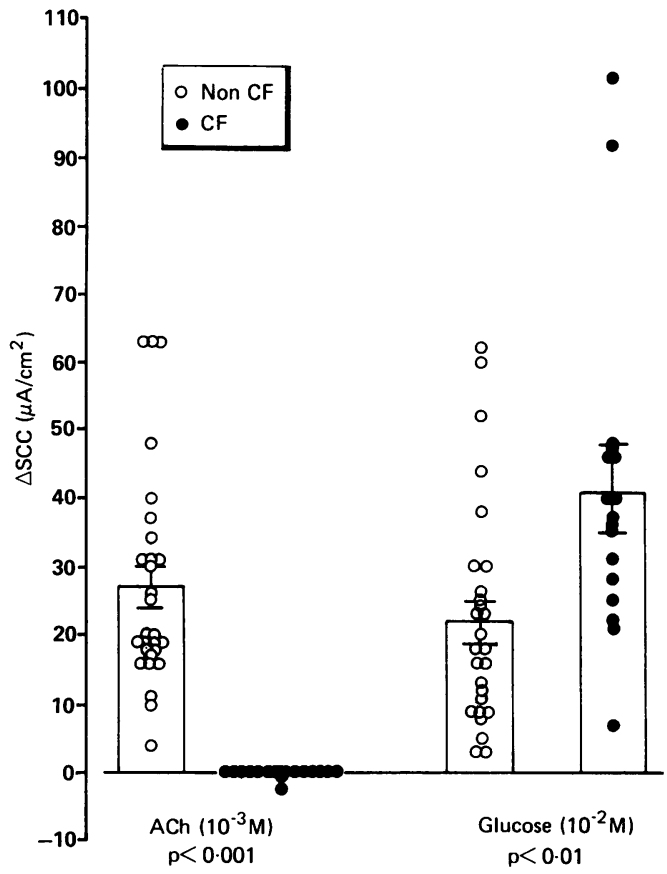

Figure 1: Change in short-circuit current $(\triangle S C C)$ across intestinal biopsy specimens from control (non-CF, $n=28)$ and cystic fibrosis ( $C F, n=17)$ patients induced by acetylcholine ( ACh, $10^{3} \mathrm{M}$ in serosal solution) or glucose $(10 \mathrm{mM}$ in mucosal solution). The bars represent mean (SE) values of the number of individual observations indicated. An unpaired $\mathrm{t}$ test was used to assess significance.

\section{STATISTICAL ANALYSIS}

Results are expressed as mean (SE) values of the number of observations indicated. The significance of the differences between control and cystic fibrosis groups was determined using an unpaired Student's $t$ test. Analysis of the data in Figure 1 showed the distribution to be skewed so a $\log$ transformation was applied.

\section{Results}

In the 28 control biopsy specimens the mean basal potential difference was $1 \cdot 8(0 \cdot 1) \mathrm{mV}$, the short-circuit current was $52.5(3.4) \mu \mathrm{A} / \mathrm{cm}^{2}$, and the tissue resistance was $35 \cdot 7(2 \cdot 8) \mathrm{ohm} . \mathrm{cm}^{2}$. The mean potential difference and short-circuit current values of the 17 cystic fibrosis biopsy specimens were significantly lower at $0.5(0.2)$ $\mathrm{mV}$ and $11.6(6.0) \mu \mathrm{A} / \mathrm{cm}^{2}$ respectively $(\mathrm{p}<0.001$ in both cases) but the tissue resistance

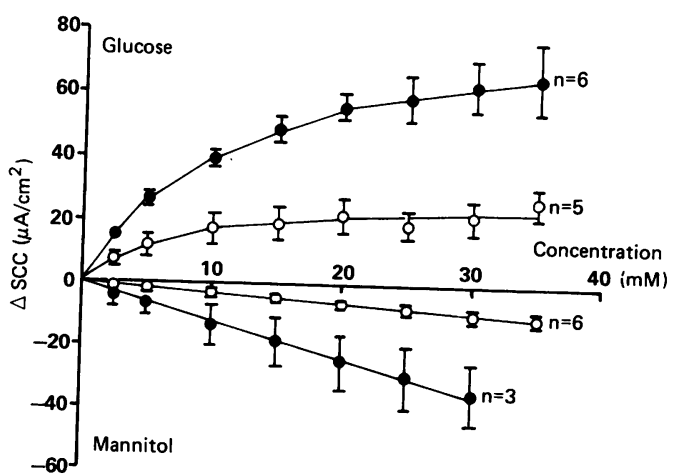

Figure 2: Relation between the concentration of glucose or mannitol and the change in short-circuit current $(\triangle S C C)$ in control $(O)$ and cystic fibrosis (O) tissues. Each point represents the mean $(S E)$ of the number of observations indicated. was similar $\left(36.5(2 \cdot 2)\right.$ ohm.cm $\left.{ }^{2}, \mathrm{p}>0.05\right)$. The 28 control biopsy specimens all responded to serosal application of the intestinal secretagogue acetylcholine $\left(10^{-3} \mathrm{M}\right)$ with a rise in the shortcircuit current $\left(27 \cdot 1(3 \cdot 0) \mu \mathrm{A} / \mathrm{cm}^{2}\right)$, but the 17 biopsy specimens from cystic fibrosis patients failed to exhibit such a response $(-0 \cdot 2(0 \cdot 2) \mu \mathrm{A} /$ $\left.\mathrm{cm}^{2}, \mathrm{p}<0.001\right)$, consistent with the absence of a functioning $\mathrm{Cl}^{-}$secretory mechanism (Fig 1).

Glucose ( $10 \mathrm{mM}$ added mucosally) increased the short-circuit current in both control and cystic fibrosis biopsy specimens but this effect was significantly greater in the cystic fibrosis group (control $=22.4 \quad(3.0) \quad \mu \mathrm{A} / \mathrm{cm}^{2}$, cystic fibrosis $=41 \cdot 2(5 \cdot 8) \mu \mathrm{A} / \mathrm{cm}^{2}, \mathrm{p}<0.01$, Fig 1). The concentration-dependence of this effect was examined and it was found that the rise in the short-circuit current induced by glucose was enhanced in the cystic fibrosis group over the entire range of concentrations tested (Fig 2).

Mannitol reduced the short-circuit current in both control and cystic fibrosis tissues but the magnitude of this change was greater in the cystic fibrosis group (control $(n=6)=3.5(0.9)$ $\mu \mathrm{A} / \mathrm{cm}^{2} / 10 \mathrm{mM}$; cystic fibrosis $(\mathrm{n}=3)=12.6$ (5.1) $\mu \mathrm{A} / \mathrm{cm}^{2} / 10 \mathrm{mM}, \mathrm{p}<0 \cdot 05$ ). With this osmotic effect considered, the rise in the shortcircuit current associated with $\mathrm{Na}^{+}$-linked glucose absorption was calculated and a kinetic analysis of the data performed. Two methods of determining the apparent $\mathrm{K}_{\mathrm{t}}$ (transport constant) and $\mathrm{J}_{\max }$ (maximum rate of transport) were used - the direct linear plot $^{7}$ and the EadieHofstee plot. ${ }^{8}$ These produced values that did not differ significantly ( $p>0.05$ in all cases). The apparent $\mathrm{K}_{\mathrm{t}}$ values were similar in control and cystic fibrosis tissues (control $(n=7)=23 \cdot 0(10 \cdot 2)$ $\mathrm{mM}$, cystic fibrosis $(\mathrm{n}=6)=27.8(4 \cdot 5) \mathrm{mM}$, $\mathrm{p}>0.05$ ) but the cystic fibrosis tissues had a significantly greater $\mathrm{J}_{\max }$ (control $=74.0(10.8)$ $\mu \mathrm{A} / \mathrm{cm}^{2}$, cystic fibrosis $=195.0(20.3) \mu \mathrm{A} / \mathrm{cm}^{2}$, $\mathrm{p}<0.001$ ). Alanine produced a similar pattern of results with an enhanced $J_{\max }$ in the cystic fibrosis group (control $(n=6)=57 \cdot 3(5 \cdot 6) \mu \mathrm{A} /$ $\mathrm{cm}^{2}$, cystic fibrosis $(\mathrm{n}=4)=110.8(15.4) \mu \mathrm{A} / \mathrm{cm}^{2}$, $p<0.01)$ and apparent $K_{t}$ values that did not differ from one another (control=32.3 (8.9) $\mathrm{mM}$, cystic fibrosis $=39 \cdot 8(7 \cdot 9) \mathrm{mM}, \mathrm{p}>0.05)$.

\section{Discussion}

This investigation has confirmed, with an increased number of patients, that the secretory response of the intestine is absent in cystic fibrosis (Fig 1). The lack of response to secretagogue challenge has also been observed in larger sheets of ileal tissue obtained from children with cystic fibrosis who were undergoing bowel resection, and ion flux determinations in some of these tissues have confirmed the absence of $\mathrm{Cl}^{-}$ secretion.' In addition, the present study has shown that the rise in the short-circuit current associated with $\mathrm{Na}^{+}$-linked glucose transport is increased over the range of concentrations tested (Figs 1 and 2). This difference was not evident in previous investigations using larger intestinal sheets ${ }^{1}$ but the number of subjects studied was much smaller (five control and three cystic fibrosis subjects). Similarly the difference was not noted in earlier studies of biopsy samples, ${ }^{23}$ 
where again only a small number of tissues was investigated. Since the increased electrical activity induced by glucose is directly related to the rate of active glucose transport, ${ }^{9}$ the results obtained in the present study suggest an enhanced active uptake of glucose in cystic fibrosis. In vivo perfusion studies have also shown an increased glucose uptake by the jejunum in cystic fibrosis, although this was attributed to a decrease in intestinal diffusion barriers. ${ }^{10}$ In these studies glucose absorption was measured as luminal loss, which occurs by both active transport and passive diffusion." Enhanced glucose uptake in cystic fibrosis was observed at lower concentrations, when active transport predominates. This is consistent with the findings of the present study which indicate that the active component of glucose absorption is increased. Amino acid absorption has also been determined in cystic fibrosis but no consistent pattern has emerged. Some groups have reported normal or increased uptake, ${ }^{1012}$ while others observed a reduction..$^{12}{ }^{13}$ In these studies, however, the total uptake of amino acids was measured rather than their active transport, while the present study indicates that active absorption is increased.

The imposition of an osmotic gradient across the intestine leads to the development of an electrokinetic potential ${ }^{14}$ and a consequent decrease in the short-circuit current. This arises from the bulk flow of fluid across the tissue which displaces mobile ions through charged junctions, induces a boundary diffusion potential by diluting ions in the unstirred layer immediately adjacent to the membrane, and generates a profile asymmetry potential by distorting ion concentration profiles within the membrane. ${ }^{7}$ To determine the change in the short-circuit current associated with $\mathrm{Na}^{+}$-linked glucose absorption, this osmotic effect must be taken into account. This was achieved by measuring the decreases in the short-circuit current induced by equimolar concentrations of mannitol. In cystic fibrosis tissues the effect of mannitol was greater than in control tissues and this can be explained in terms of a reduced $\mathrm{Cl}^{-}$ permeability in the former group.

A kinetic analysis of intestinal transport has several problems. ${ }^{7}$ A significant unstirred layer at the luminal membrane impedes access of the transported nutrient to its carrier sites, leading to artificially high $\mathrm{K}_{\mathrm{t}}$ values. Moreover, since:

$$
\text { apparent } \mathrm{K}_{\mathrm{t}}=\text { real } \mathrm{K}_{\mathrm{t}}+\mathrm{J}_{\max } \mathrm{d} / \mathrm{D}^{7}
$$

(where $\mathrm{d}$ is the effective thickness of the unstirred layer and $\mathrm{D}$ is the free diffusion coefficient), a change in $\mathrm{J}_{\max }$ also leads to an alteration in the calculated apparent $\mathrm{K}_{\mathrm{t}}$ value. The increased $\mathrm{J}_{\max }$ in the cystic fibrosis tissues was not accompanied by a rise in the apparent $K_{t}$. Thus either the real $K_{t}$ is reduced or there is a change in $d$ or $D$. Abnormal mucoid secretion in cystic fibrosis ${ }^{15}$ could lead to a change in both the thickness of the unstirred layer (d) and the diffusion coefficient of nutrients (D). Both these points require further investigation. The $\mathrm{J}_{\max }$ values can, however, provide useful information about the operation of the active nutrient transport mechanisms in cystic fibrosis, although it is difficult to draw valid conclusions from the apparent $K_{t}$ values. The increased $\mathrm{J}_{\max }$ indicates that the enhanced glucose response in cystic fibrosis results from a rise in the maximum capacity of the active transport process. This is in contrast to the finding of an in vivo study which showed no change in $J_{\max }$ but a decrease in apparent $K_{t}$ which was attributed to a reduction in intestinal diffusion barriers in cystic fibrosis, ${ }^{10}$ but this was based on measurements that included both active and passive components. The electrical response to glucose reflects the behaviour of the active electrogenic component of glucose absorption only, and this was increased in the cystic fibrosis group. Similarly, the increased $\mathrm{J}_{\max }$ for the rise in the short-circuit current induced by alanine suggests that the active transport of this amino acid is also enhanced in cystic fibrosis.

It has been shown in this study that the absence of functioning $\mathrm{Cl}^{-}$channels on the apical membrane of the enterocyte is not associated with impaired glucose absorption. Thus the opening of these channels in the presence of an actively transported nutrient does not seem to be essential for the active transport process. On the contrary, the lack of $\mathrm{Cl}^{-}$channel activity may lead to an increased membrane potential at the luminal border of the enterocyte, providing a greater driving force for $\mathrm{Na}^{+}$-linked nutrient entry, and this could explain the enhanced glucose and alanine transport observed in this study. Such an explanation would suggest that the $\mathrm{Na}^{+}$-dependent active transport of all nutrients may be enhanced in cystic fibrosis. Thus the abnormalities in the luminal phase of digestion observed in this disease do not seem to be exacerbated by a reduction in nutrient absorption by the enterocytes. In cystic fibrosis the disorder of intestinal transport is not restricted to a defect in the secretory mechanism as active nutrient absorption is enhanced as well. Since net solute transport across the intestine provides the driving force for fluid movement, ${ }^{16}$ the increase in net solute movement out of the intestinal lumen could lead to dehydration of the luminal contents and contribute to the intestinal complications of this disease, such as distal ileal obstruction syndrome.

This study had Ethical Committee approval.

We gratefully acknowledge financial support from Janssen Pharmaceutical Ltd. We thank Dr R J Levin for his helpful comments and advice on this manuscript.

1 Berschneider HM, Knowles MR, Azizkhan RG, et al. Altered intestinal chloride transport in cystic fibrosis. FASEB $\mathcal{F}$ 1988; 2: 2625-9.

2 Taylor CJ, Baxter PS, Hardcastle J, Hardcastle PT. Absence of secretory response in jejunal biopsy samples from children with cystic fibrosis. Lancet 1987; ii: 107-8.

3 Taylor CJ, Baxter PS, Hardcastle J, Hardcastle PT. Failure to induce secretion in jejunal biopsies from children with cystic fibrosis. Gut 1988; 29: 957-62.

4 Welsh MJ, Fick RB. Cystic fibrosis. $\mathcal{F}$ Clin Invest 1987; 80: 1523-6.

5 Giráldez F, Sepúlveda FV. Changes in the apparent chloride permeability of Necturus enterocytes during the sodiumcoupled transport of alanine. Biochim Biophys Acta 1987; 898: 248-52.

6 Boyd CAR. Absence of secretory response in jejunal biopsy samples from children with cystic fibrosis. Lancet 1987; ii: 389.

7 Levin RJ. Fundamental concepts of structure and function of the intestinal epithelium. In: HL Duthie, KG Wormsley, eds. Scientific basis of gastroent 
8 Engel PC. Enzyme kinetics. 2nd edn. London: Chapman and Hall, 1981: 14-25.

9 Luppa D, Hartenstein H, Müller F. Relation between microvilli membrane potential and glucose transport capacity of rat small intestine. Biomed Biochim Acta 1987; 46: 341-8.

10 Frase LL, Strickland AD, Kachel GW, Krejs GJ. Enhanced glucose absorption in the jejunum of patients with cystic glucose absorption in the jejunum of patient
fibrosis. Gastroenterology 1985; 88: 478-84.

11 Debnam ES, Levin RJ. An experimental method of identifying and quantifying the active transfer electrogenic component from the diffusive component during sugar absorption in vivo. $\mathcal{F}$ Physiol 1975; 246: 181-96.
12 Milla PJ, Kilby A, Rassam UB, Ersser R, Harries JT. Small intestinal absorption of amino acids and a dipeptide in pancreatic insufficiency. Gut 1983; 24: 818-24.

13 Morin CL, Roy CC, Lasalle R, Bonin A. Small bowel mucosal dysfunction in patients with cystic fibrosis. $\mathcal{F}$ Pediatr 1976; 88: 213-6.

14 Smyth DH, Wright EM. Streaming potentials in the rat small intestine. I P hysiol 1966; 182: 591-602.

15 Eggermont $E$. The role of the small intestine in cystic fibrosis patients. Acta Paediatr Scand 1985; (suppl 317): 16-21.

16 Hendrix TR, Bayless TM. Digestion: intestinal secretion. Ann Rev Physiol 1970; 32: 139-64. 